\title{
Mechanical Properties Investigation of Composite Sandwich Panel and Validation of FEM Analysis
}

\author{
Szymon Jakubiak ${ }^{1, a}$, Filip Ćwikła ${ }^{2, b}$, Witold Rządkowski ${ }^{3, c}$ * \\ ${ }^{1-3}$ Faculty of Power and Aeronautical Engineering, Warsaw University of Technology, \\ Nowowiejska 24, 00-665 Warsaw, Poland \\ aszymonjakubiak@wutracing.pl, bfilipcwikla@wutracing.pl, 'cwitold.rzadkowski@pw.edu.pl
}

Keywords: Composites, Carbon Fibers, Epoxy Resin, Tensile Test, Aluminum Honeycomb Sandwich

\begin{abstract}
Composite sandwich structures allows for significant mass reduction compared with traditional steel frames used in Formula Student bolides. However, in order to reach a full potential of composite monocoque chassis and ensure safety of the driver, it is required to perform physical tests of sandwich structure and its elements, supported with FEM analysis. Mechanical properties of sandwich panel are affected by a variety of factors, including but not limited to, manufacturing technique and curing conditions. Therefore, series of experiments were performed to determine in-plane tensile, compressive and shear properties of skin material fabricated in conditions related to those projected for monocoque. The acquired data was compared with expected results and used in further FEM analysis. Apart from uniaxial tensile tests, the whole sandwich structure, was tested in 3-point bending and "punch through" strength. A FEM model of each test was created in order to validate a data from more complex simulations.
\end{abstract}

\section{Introduction}

Mechanical properties of CFRP composites depend heavily on performed manufacturing process. Therefore, a series of tests is essential in order to achieve reasonable design, without oversizing the structure.

Main parameters required in design of composite monocoque for Formula Student competition were Young's modulus of laminates, energy absorbed by composite sandwich panel and perimeter shear strength of skin material.

Similar studies of laminates [1,2] and sandwich panels [3-6] were conducted in the past.

Bending and shear tests were performed in accordance with Formula SAE Rules[7] in regards to side impact structure requirements, i.e. punch through strength and energy absorption in bending.

\section{Methods}

All tests were performed on Instron 8516 Testing System.

Young's modulus of laminates was derived from uniaxial tensile test. All specimens were prepared in accordance with ASTM 3039[8]. E-glass tabs were laminated to each carbon fibre laminate.

First group of test samples was made of Tenax UTS50 12K F22 S carbon fibre tow infused during wet lay-up with Havel epoxy resin LH 385.

Wet lay-up is a method used for manufacturing wide range of components for Formula Student bolides e.g. front and rear wings, diffuser and sidepods. 
Table 1. Configuration of samples from wet lay-up

\begin{tabular}{|c|c|}
\hline lay-up & number of specimens \\
\hline$[0]$ & 8 \\
\hline$\left[0_{2}\right]$ & 12 \\
\hline
\end{tabular}

Second group of specimens was manufactured in prepreg technology from KORDCARBONCPREG-200-P-3K-EP1-42, cured in $120^{\circ} \mathrm{C}$ in a vacuum bag under atmospheric pressure.

Prepreg technology is used for manufacturing composite monocoque of the bolide. This method allows for cutting time of manufacturing and increasing consistency of properties.

Table 2. Configuration of prepreg samples

\begin{tabular}{|c|c|}
\hline lay-up & number of specimens \\
\hline$[0]$ & 1 \\
\hline$\left[0_{3}\right]$ & 3 \\
\hline$\left[45_{3}\right]$ & 1 \\
\hline$[0 / 45 / 0]$ & 1 \\
\hline
\end{tabular}

A load-displacement curve was obtained directly from testing machine. Resulting strain was compared with strain from Digital Image Correlation, necessary calibration was introduced.

All specimens were covered in stochastic pattern and then recorded in UHD 30fps throughout the whole tensile test. With the use of extensometers in GOM Correlate software, longitudinal strain was calculated for every frame of recorded video.

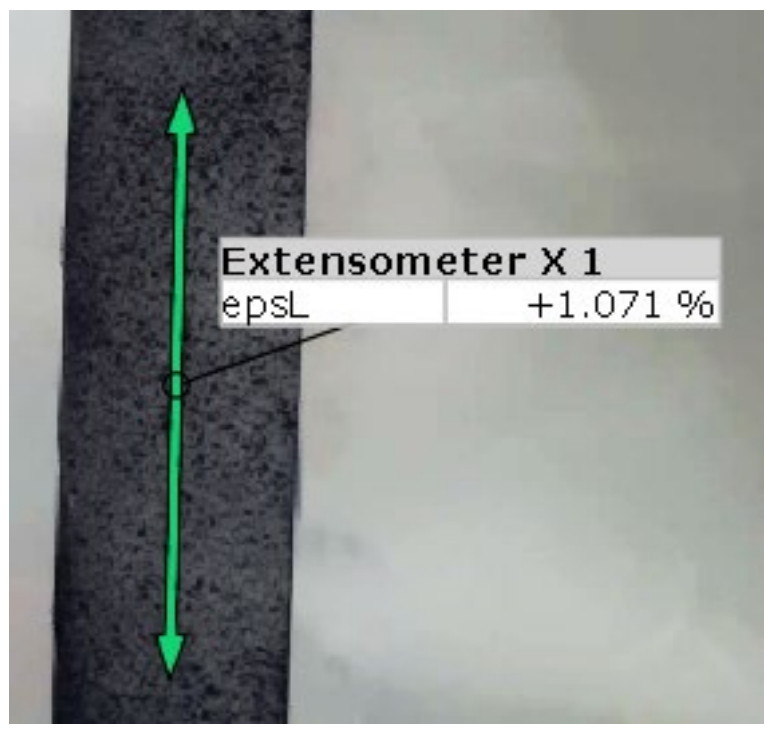

Fig. 1. Extensometer created from 2 points based on stochastic pattern

Rectangular 275 mm x 500 mm composite sandwich panels were tested in 3-point bending. Panels were supported by a span distance of $400 \mathrm{~mm}$. Energy absorbed in total displacement of $19 \mathrm{~mm}$ was compared with energy absorbed by two $25 \mathrm{~mm} \times 1.75 \mathrm{~mm}$ round steel tubes bended on the same test rig, to prove structural equivalency of composite side impact structures in bolide with monocoque. Steel force applicator with $50 \mathrm{~mm}$ radius overhang test sample at both ends in order to prevent edge loading. 


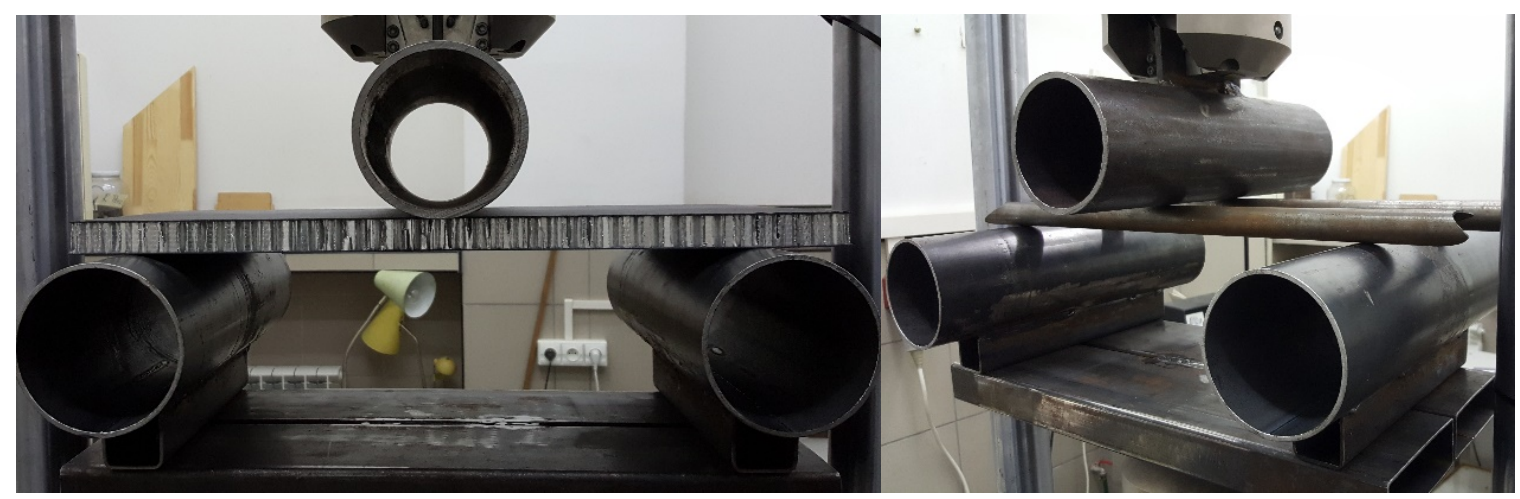

Fig. 2. Composite (left) and steel (right) samples placed on the test rig

Sandwich panels cores (20 mm thick) were made of 3003 aluminium alloy. Cell size of the honeycomb was $6.4 \mathrm{~mm}$ with nominal foil gauge of $0.075 \mathrm{~mm}$. Material used for skin was Kordcarbon prepreg. For interface between core and skin materials, XPREG XA120 Prepreg Adhesive Film was used. All test samples were symmetric i.e. fibre orientation in skins was symmetric about panel midplane.

Table 3. Configuration of samples for 3-point bending

\begin{tabular}{|c|c|c|}
\hline sample id & skin lay-up & adhesive film \\
\hline 1b & {$[0 / 45]$} & no \\
\hline 2b & {$[0 / 45 / 0]$} & yes \\
\hline 3b & {$[0 / 45 / 0 / 45]$} & yes \\
\hline
\end{tabular}

Perimeter shear strength was derived from first highest force peak in punch through test, in which a steel $\varnothing 25 \mathrm{~mm}$ punch was pushed against a sandwich panel supported by steel plate with cylindrical Ø32 $\mathrm{mm}$ hole for the punch.

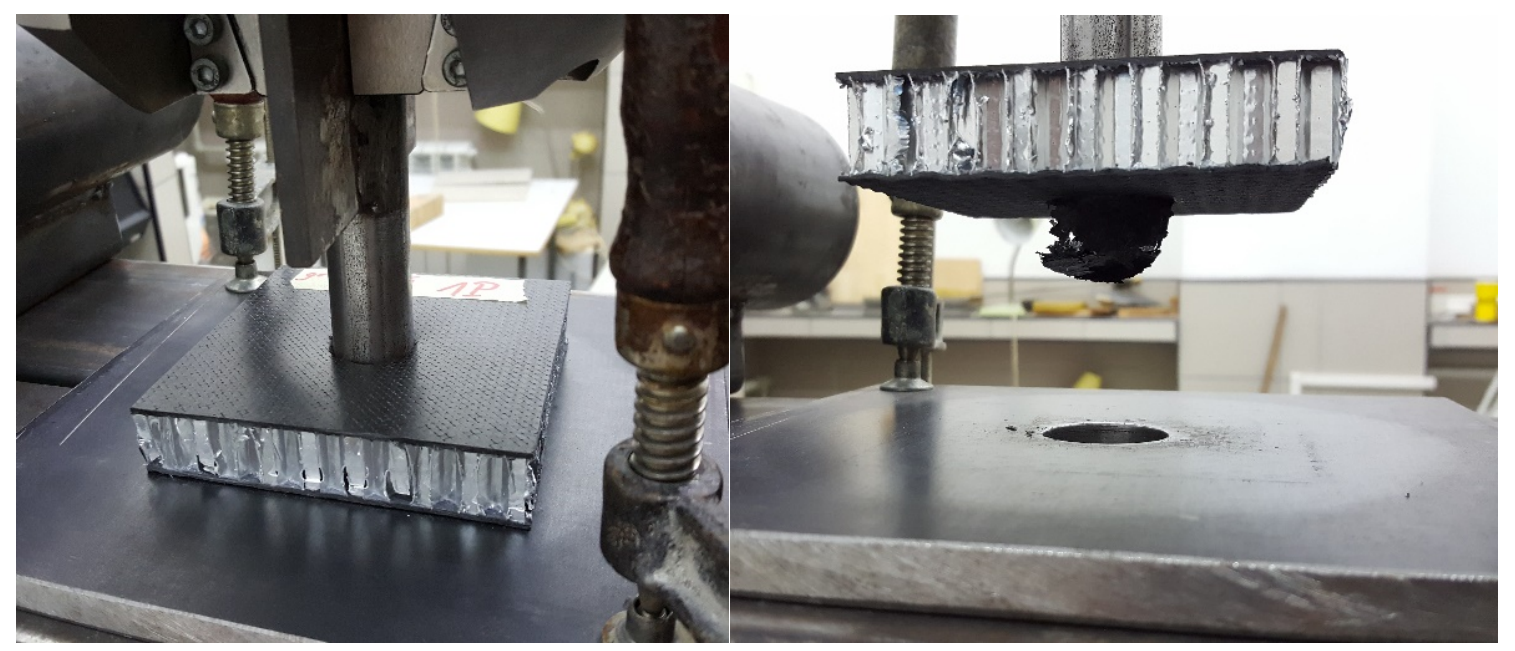

Fig. 3. Setup for punch-through test

Square $100 \mathrm{~mm}$ x $100 \mathrm{~mm}$ panel samples were manufactured under the same conditions and from same materials as specimens for 3-point bending. The aim of this test is to provide data for inserts design and to ensure safety of the driver in case of collision with a random debris on a track. 
Table 4. Configuration of samples for punch-through test

\begin{tabular}{|c|c|c|}
\hline sample id & skin lay-up & adhesive film \\
\hline $2 p$ & {$[45 / 0 / 45]$} & yes \\
\hline $3 p$ & {$[45 / 0 / 45 / 0 / 45]$} & yes \\
\hline $1 p$ & {$[45 / 0 / 45 / 0 / 45 / 0 / 45]$} & yes \\
\hline
\end{tabular}

\section{Results and Discussion}

Each sample for tensile test was mounted on tensile test machine and loaded until failure. Average results are presented in Table 5, 6. The data scatter of Young's modulus is acceptable and tested values may be used in further design and FEM analyses.

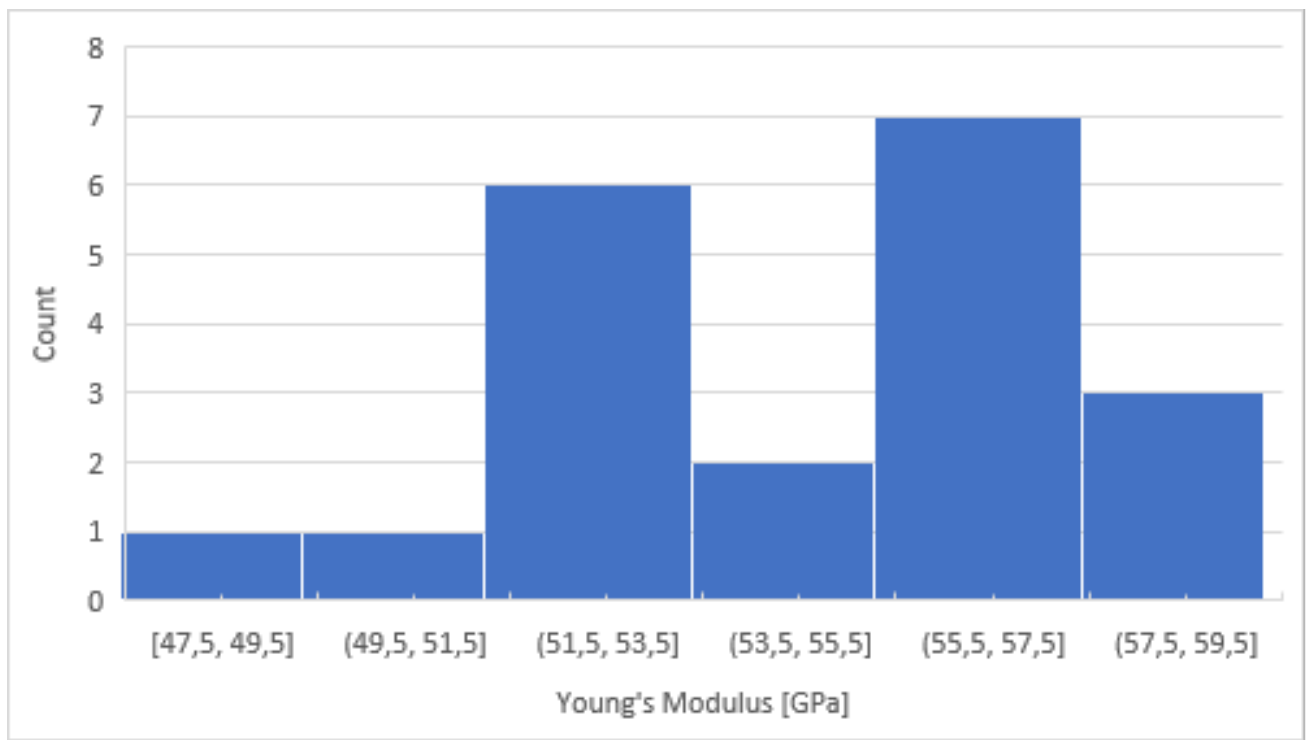

Fig. 4. Distribution of Young's modulus for wet lay-up samples

Table 5. Average results for wet lay-up samples

\begin{tabular}{|c|c|c|c|}
\hline & $\begin{array}{c}\text { Young's Modulus } \\
{[\mathrm{GPa}]}\end{array}$ & $\begin{array}{c}\text { Strain to Failure } \\
{[\%]}\end{array}$ & $\begin{array}{c}\text { Tensile Strength } \\
{[\mathrm{MPa}]}\end{array}$ \\
\hline measured & 54,7 & 1,70 & 740 \\
\hline
\end{tabular}

Table 6. Average results for prepreg samples correlated with data from vendor

\begin{tabular}{|c|c|c|c|}
\hline & $\begin{array}{c}\text { Young's Modulus } \\
{[\mathrm{GPa}]}\end{array}$ & $\begin{array}{c}\text { Strain to Failure } \\
{[\%]}\end{array}$ & $\begin{array}{c}\text { Tensile Strength } \\
{[\mathrm{MPa}]}\end{array}$ \\
\hline datasheet & 58,6 & 1,3 & 778 \\
\hline measured & 57,9 & 1,01 & 508 \\
\hline
\end{tabular}

Most common failure point of the samples was located near tab ends, Figure 5. Due to stress concentration at this points, measurements of nominal values of ultimate strain and tensile strength for laminates was not possible. However, Young's modulus derived from linear-elastic region meet their expected values. 




Fig. 5. Failure mode of tensile test specimen

Sandwich panels in 3-point bending shows long liner region until a failure of the skin on compressed side of the sample, Figure 7, 8. Properly estimated stiffness of sandwich panels is crucial in further FEA of monocoque chassis.



Fig. 6. Load-deflection curve for bended sandwich panels 


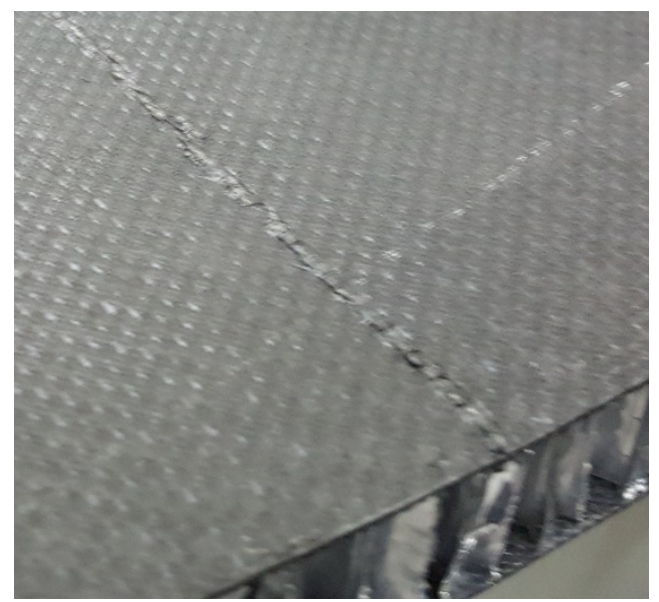

Fig. 7. Failure of compressed skin in sandwich panel

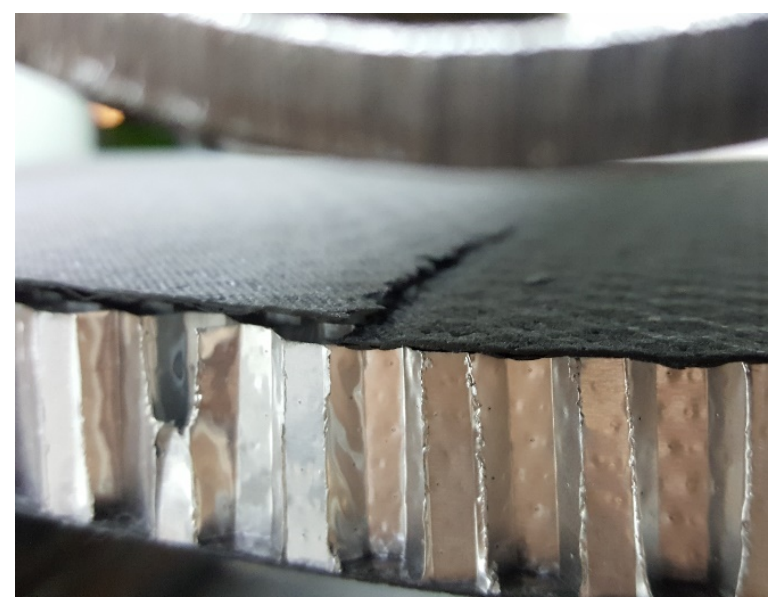

Fig. 8. Failure of skin in compression and core delamination

Tested panels failure starts from skin compression. Samples with adhesive film keep absorbing energy after first ply failure, while the one without adhesive layer loses its load carrying capacity after skin delamination. This comparison shows an importance of using adhesive film which prevents a skin from premature delamination.

Table 7. Energy absorbed on $19 \mathrm{~mm}$ displacement

\begin{tabular}{|c|c|c|c|c|}
\hline & 1b & 2b & $3 b$ & tubes \\
\hline $\begin{array}{c}\text { Absorbed } \\
\text { energy [J] }\end{array}$ & 23 & 43 & 59 & 96 \\
\hline
\end{tabular}

Based on results from tensile test a FEM model of 3-point bending was created. The shell elements allows for further scaling of the simulation up to the analysis of the whole monocoque structure leaving computing power requirements on a reasonable level. The boundary conditions (Figure 9) come down to fixed support tube (B), 0 displacement on one edge of a panel (A) and respective displacement on force applicator resulting in the highest load measured during the bending test (C). Contact between a panel and force applicator was set to frictionless while for support tube there was fictional contact with a friction coefficient of 0,2. 

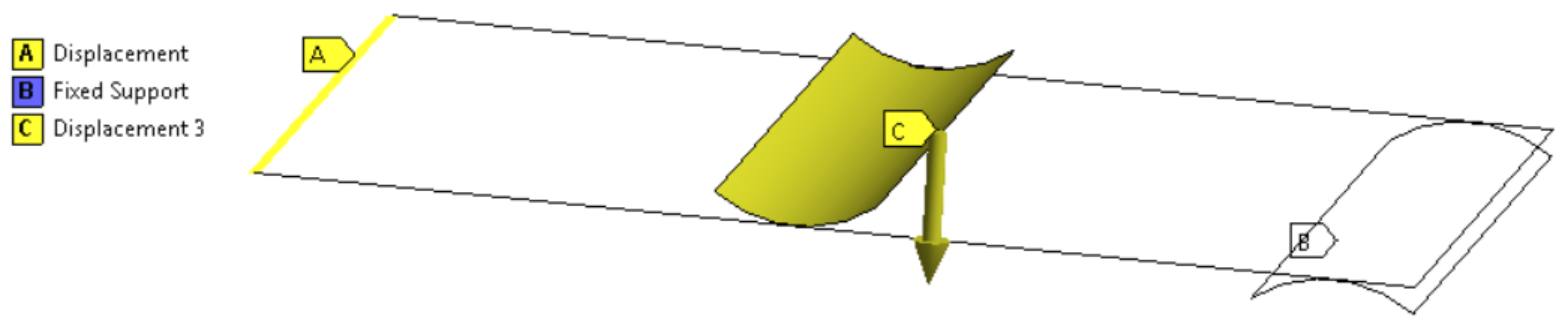

Fig. 9. Boundary conditions for a panel in 3-point bending

With global element size of $10 \mathrm{~mm}$ the accuracy of discretization was sufficient. In comparison to $2,5 \mathrm{~mm}$ element size there is $5 \%$ difference in results. Critical stress values for FEA were calibrated on b3 case so that it indicates first ply failure during the highest load from physical test. This approach results in inverse reserve factors for b1 and b2 cases respectively 1,10 and 0,90 .
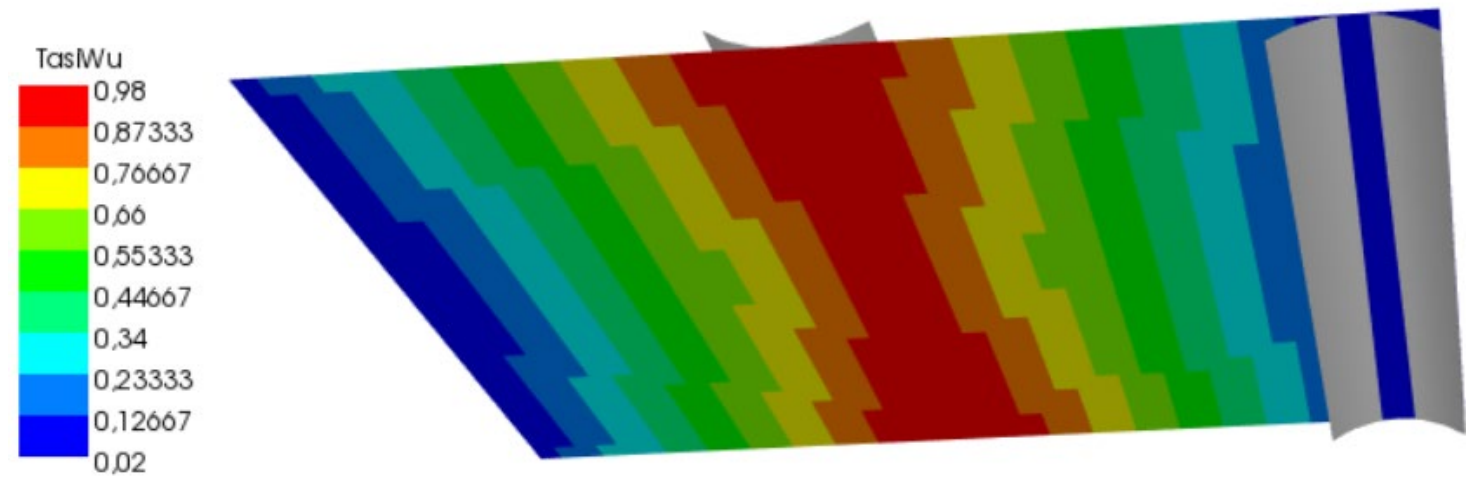

Fig. 10. Tsai-Wu criterion for b3 panel under 10,4kN load

Results from punch-through test show linear relation between thickness of the skin laminate and maximum force recorded during the test. The differences between highest force peaks during punching through the top and the bottom laminate are more significant for samples with higher thickness.

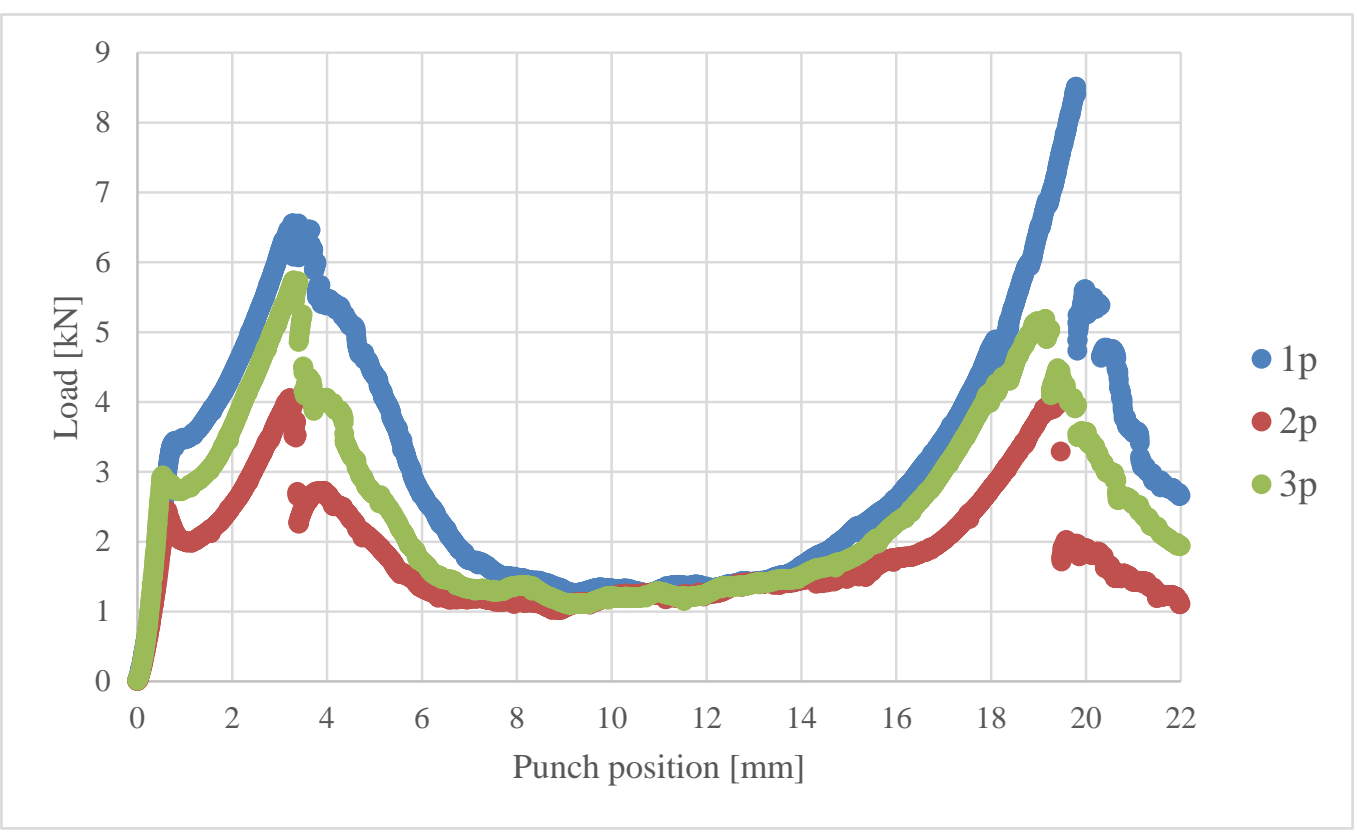

Fig. 11. Load-deflection curve for punch-through test 


\section{Conclusion}

Tensile test allowed for determination of Young's modulus for different laminates with the accuracy sufficient for design of Formula Student bolide. Further improvement of sandwich panels is required in order to provide higher energy absorption in bending.

Both prepreg and wet laminate present similar values of Young's modulus while UTS50 carbon fibre shows superior strength properties over its prepreg counterpart and should be taken under consideration in design of highly loaded composite parts.

FEA estimation of first ply failure varies by $\pm 10 \%$ between different panels in comparison with physically tested values. This deviation may be caused by local stresses introduced by a force applicator or overall scatter in panels properties.

\section{References}

[1] J.M.F de Paiva, S. Mayer, M.C. Rezende, Comparison of tensile strength of different carbon fabric reinforced epoxy composites, Mat. Res. vol.9 no.1 São Carlos Jan./Mar. 2006. https://doi.org/10.1590/s1516-14392006000100016

[2] H. Rahmani, S.H.M. Najafi, S.S. Matin, A. Ashori, Mechanical Properties of Carbon Fiber/Epoxy Composites: Effects of Number of Plies, Fiber Contents, and Angle-Ply Layers, Polymer Engineering and Science 54(11) November 2014. https://doi.org/10.1002/pen.23820

[3] G. Sun, X. Huo, D. Chen, Q. Li, Experimental and numerical study on honeycomb sandwich panels under bending and in-panel compression, Materials \& Design vol.133, 5 Nov. 2017, pp. 154-168. https://doi.org/10.1016/j.matdes.2017.07.057

[4] D. Ruan, G. Lu, Y.C. Wong, Quasi-static indentation tests on aluminium foam sandwich panels, Composite Structures, 92, (2010), 2039-2046.

https://doi.org/10.1016/j.compstruct.2009.11.014

[5] Chen, C., Harte, A.-M., and Fleck, N. A., 2000, The Plastic Collapse of Sandwich Beams With a Metallic Foam Core, Int. J. Mech. Sci., 43, pp. 1483-1506. https://doi.org/10.1016/s00207403(00)00069-2

[6] H. Bart-Smith, J. W. Hutchinson, A. G. Evans, , Measurement and Analysis of the Structural Performance of Cellular Metal Sandwich Construction, Int. J. Mech. Sci., 43, pp. 1945-1963. (2011). https://doi.org/10.1016/s0020-7403(00)00070-9

[7] Formula SAE Rules 2019 v2.1, SAE International, pp. 36-37. (2018)

[8] ASTM D3039, Standard Test Method for Tensile Properties of Polymer Matrix Composite Materials, American Society for Testing Materials. 